\title{
Possible mechanisms of sudden cardiac death in top athletes: a basic cardiac electrophysiological point of view
}

\author{
András Varró ${ }^{1,2 *}$ and István Baczkó ${ }^{1}$ \\ ${ }^{1}$ Department of Pharmacology and Pharmacotherapy, Faculty of Medicine, Albert Szent- \\ Györgyi Medical Centre, University of Szeged, Szeged, Hungary; \\ ${ }^{2}$ Research Unit for Cardiovascular Pharmacology, Hungarian Academy of Sciences, Szeged, \\ Hungary.
}

Running title: Sudden cardiac death in athletes

*Corresponding author:

András Varró, M.D., Ph.D., D.Sc.

Department of Pharmacology and Pharmacotherapy

Faculty of Medicine, University of Szeged

H-6721 Szeged, Dóm tér 12. Hungary

Phone: + 36.62.545-683; Fax: + 36.62.545-680

E-mail: a.varro@phcol.szote.u-szeged.hu 


\begin{abstract}
Sudden death among athletes is very rare (1:50 000-1:100 000 annually) but it is still 2-4 times more frequent than in the age-matched control population and attracts significant media attention. We propose a mechanism underlying sudden cardiac death in athletes that does not relate to myocardial ischaemia but is based on repolarization abnormalities due to potassium channel down-regulation and can also be best explained by the concurrent presence of several factors such as cardiac hypertrophy (athlete's heart), and/or hypertrophic cardiomyopathy, increased sympathetic tone, genetic defects, drugs, doping agents, food or dietary ingredients. These factors together can increase the repolarization inhomogeneity of the heart ("substrate") and an otherwise harmless extrasystole ("trigger") occurring with a very unfortunate timing may sometimes induce life threatening arrhythmias. The effective and possible prevention of sudden cardiac death requires the development of novel cost effective cardiac electrophysiological screening methods. Athletes identified by these tests as individuals at higher proarrhythmic risk should then be subjected to more costly genetic tests in order to uncover possible underlying genetic causes for alterations in ionic channel structure and/or function.
\end{abstract}

Keywords sudden cardiac death, competitive athletes, athlete's heart, arrhythmia, repolarization abnormality 


\section{Introduction}

Although there is no doubt that physical exercise and competitive sport are healthy, improving quality of life and life expectancy, a number of tragic sudden deaths involving young competitive athletes were reported in the press in recent years.

Fortunately, sudden death among athletes is rare, approximately 1:50 $000-1: 100000$ $[30,37]$, however, it is likely that the real prevalence is underestimated by these statistics. Even when different statistics are considered, sudden cardiac death (SCD) has been shown to be 2 to 4 times more frequent in young athletes compared to their age-matched population with no sports activities [14]. In only the minority of cases the cause of SCD is satisfactorily established (e.g. trauma, aneurism rupture, acute asthmatic attack, shock etc.) and mostly SCD is attributed to ventricular fibrillation. In cases where autopsy findings are inconclusive, the ischaemic origin of SCD is often suspected without hard evidence. This explanation can be questioned for several reasons. It is compelling that SCD in athletes does not usually happen at peak performance, when oxygen demand is the highest in the myocardium, but during warmup, after training or during a relatively inactive period of a football game and signs of cardiac ischaemia on the ECG or proof of myocardial infarction is very rarely observed during or following these events. Furthermore, regular training can be considered as one of the most effective activities due to its cardiac preconditioning (antiarrhythmic and antiischaemic) effect $[26,33]$ increasing the chance for survival during these episodes.

Thus, the cause and mechanism of SCD in competitive athletes must be sought elsewhere.

\section{The proposed mechanism of arrhythmias leading to sudden cardiac death in competitive athletes}

In normal circumstances, conduction in the heart is fast $(1-2 \mathrm{~m} / \mathrm{s})$ and the duration of the action potential in myocardial cells is long (200-300 ms). Thus these cells are unable to become stimulated early, since they are in a refractory state, the length of which can be characterized by the effective refractory period (ERP). Importantly, in the normal setting the difference between the action potential durations and consequently the ERPs of adjacent cells is very small, thus repolarization is homogenous. Fast conduction and homogenous repolarization (and refractory period) together prevent the circular re-entry of excitation and arrhythmia will not develop. 
On the other hand, when the duration of repolarization and consequently the refractory period of the myocardium is prolonged, the differences in the repolarization of adjacent cells also become larger, leading to increased spatial repolarization inhomogeneity (Fig. 1). As a consequence, an extrasystole generated after a normal sinus beat can propagate in the direction of cells with shorter action potential duration but its propagation will be blocked in the direction of cells with a longer action potential duration (Fig. 1). Thus this extra stimulus can travel back in a complicated path toward the site of its origin and everywhere else where excitability is regained and can generate a chaotic tachycardia or even ventricular fibrillation (VF). VF does not revert back to sinus rhythm spontaneously in humans and leads to SCD without intervention in a few minutes. It is very important to note that two independent factors are needed for the arrhythmia described above and illustrated schematically on Figure 1 to develop. Inhomogeneity of repolarization following prolongation of repolarization is itself not sufficient for arrhythmia development, establishing only the possibility of an arrhythmia ("substrate"). In order to induce arrhythmia, an extrasystole in the vulnerable period is needed ("trigger") that can travel the re-entry paths created by the inhomogenous repolarization. The timing of this trigger extrasystole is critical, since before the vulnerable period its conduction is blocked and after the vulnerable period it does not lead to tachycardia or fibrillation, only a harmless single extrasystole. The larger the repolarization inhomogeneity, the longer the vulnerability period and more frequent the extrasystole, the bigger the chance becomes for serious arrhythmia development. A similar mechanism for arrhythmia generation was demonstrated experimentally in dogs (Figs. 2 and 3) where the increased repolarization inhomogeneity was induced by blocking the rapid delayed rectifier potassium current $\left(\mathrm{I}_{\mathrm{Kr}}\right)$ and the trigger was elicited by external stimulation [1].

\section{Cardiac myocardial hypertrophy in athletes: an important risk factor}

It has been known for a long time that strong physical exercise in competitive athletes induces adaptation of the cardiovascular system including lower resting heart rate (increased vagal tone) and increased cardiac mass (hypertrophy) and volume as a consequence of increased demand on the cardiovascular system, called, ,athlete's heart”. This is a physiological compensatory mechanism that reverses in most cases following the termination of sports activities [3]. Lower heart rate favors prolonged repolarization and increased inhomogeneity. 
A number of echocardiography studies have proven that myocardial hypertrophy develops following long-term sports activities $[3,32,38]$ and that this hypertrophy is more pronounced in male than in female athletes and that the degree of hypertrophy varies with different types of exercise training. The most significant increase in left ventricular cavity and wall thickness (more than 75\%) was detected in cyclists, cross-country skiers, rowers, football players and water polo players, while weight lifters, fencers and wrestlers exhibited milder changes (less than $50 \%[29])$.

Interestingly, few conclusive animal experimental data is available in the literature regarding the effect of exercise training on cardiac hypertrophy, especially on the cellular level and in species that are electrophysiologically relevant to human (i.e. not mouse and rat). However, it was speculated that in such situations potassium channel down-regulation might occur [23].

It is important to emphasize that dogs with chronic atrioventricular (AV) block, as a reasonable analogue for athlete's heart, exhibit marked bradycardia, compensated and reversible myocardial hypertrophy three weeks following the induction of AV block [17, 49]. The increased duration and inhomogeneity of cardiac repolarization were observed in these animals. These dogs with chronic AV block were more susceptible to lethal ventricular arrhythmias following different challenges than the corresponding controls [51], (Fig. 4). These changes have been primarily attributed to the downregulation of the slow component of the delayed rectifier potassium current $\left(\mathrm{I}_{\mathrm{Ks}}\right)$, and to a lesser extent to the downregulation of other repolarizing potassium currents (Fig. 5), [50]. In addition, the inreased incidence of drug-induced arrhythmia correlated better with the increase in short-term beat-to-beat variability of the QT interval than with changes of the frequency corrected QT interval (QTc) [46]. It is also known that in patients with heart failure and in animals with experimental heart failure marked cardiac hypertrophy can be detected that is accompanied by prolongation of repolarization and increased arrhythmia propensity [24]. Notably, a significant number of heart failure patients die due to lethal ventricular arrhythmias and not due to failing cardiac pump function at the earlier stages of heart failure [31]. Evidence suggests that the downregulation of transmembrane potassium channels, including $\mathrm{I}_{\mathrm{Ks}}$, might also be responsible for the prolongation of repolarization and increased inhomogeneity of repolarization in heart failure [24]. Whether $I_{K s}$ downregulation is a feature of the hypertrophic human heart and of the athlete's heart similarly to that shown in animal models, needs to be confirmed. In heart failure, the increased expression (mRNA and protein levels) of $I_{f}$ channels responsible for spontaneous diastolic depolarization, and of the $\mathrm{Na}^{+} / \mathrm{Ca}^{2+}$ 
exchanger (NCX) have been described $[12,39,43]$. These factors can increase the incidence of extrasystoles, serving as arrhythmia triggers. However, reliable data regarding changes in the expression of ion channels and exchangers are not available in compensated myocardial hypertrophy (e.g. in the "athlete's heart"). The reversible cardiac hypertrophy induced repolarization changes are probably mild since body surface ECG measurements did not indicate a significant increase in the duration and inhomogeneity of repolarization in competitive athletes $[22,47]$.

Therefore, compensatory cardiac hypertrophy caused by intensive training may lead to increased spatial and/or temporal inhomogeneity of repolarization and to impaired repolarization reserve. These changes in repolarization can create an arrhythmia substrate and may increase arrhythmia propensity in athletes, and albeit rarely, can contribute to sudden cardiac death when accompanied by other factors (see below).

Theoretically, the very high systolic blood pressure observed during strength exercise can also contribute to cardiac remodeling and consequently, to increased propensity for sudden cardiac death in top athletes.

\section{Increased sympathetic tone}

Sudden cardiac death or syncope in athletes usually does not occur during or immediately following peak performance, but during warmup or shortly after training, sometimes in the dressing room. At this time point, sympathetic tone is still elevated but oxygen demand does not differ from resting levels. These circumstances do not support ischaemic origin of sudden cardiac death but highlight the importance of elevated intracellular cAMP concentrations caused by increased sympathetic tone. The cellular electrophysiological consequences of increased cAMP concentrations are multiple. On the one hand, the pacemaker transmembrane current $\left(\mathrm{I}_{\mathrm{f}}\right)$ increases leading to higher heart rate and development of trigger extrasystoles [19]. On the other hand, increased intracellular cAMP enhances L-type calcium current $\left(\mathrm{I}_{\mathrm{Ca}}\right)$, resulting in increased $\mathrm{Ca}^{2+}$ entry to the cells [40]. This latter event is an important adaptive mechanism for positive inotropy besides the increase of heart rate to ensure increased cardiac output. Increased $\mathrm{Ca}^{2+}$ entry must be followed by calcium extrusion during steady state that is mostly achieved by the increased function of the $\mathrm{Na}^{+} / \mathrm{Ca}^{2+}$ exchanger (NCX) partly during diastole. At resting membrane potential, i.e. during diastole the NCX pumps out 1 calcium ion in exchange for pumping 3 sodium ions into the cell [9]. This has a depolarizing effect that can also contribute to the development of extrasystoles. 
Increased cAMP also enhances $\mathrm{I}_{\mathrm{Ks}}$ function [48] that normally shortens repolarization and counterbalances the repolarization prolonging effect of increased L-type calcium current induced by increased cAMP. However, when $\mathrm{I}_{\mathrm{Ks}}$ density is reduced by genetic mutations, or by $\mathrm{I}_{\mathrm{Ks}}$ downregulation due to cardiac hypertrophy (athlete's heart), this counterbalancing function can become impaired [21, 42] and may lead to prolongation of repolarization and/or refractory period creating an arrhythmia substrate in athletes.

In summary, increased sympathetic tone in athletes can enhance arrhythmia propensity by increasing both trigger activity (extrasystoles) and arrhythmia substrate (repolarization inhomogeneity).

\section{Additional factors}

\section{Cardiac diseases}

Hypertrophic cardiomyopathy is the most common cause of sudden cardiac death in young competitive athletes according to autopsy findings [5, 30, 37]. The disease is a familial malformation $[5,10]$, and mutations in a number of sarcomeric genes have been identified that lead to HCM and the developing cardiomegaly and interstitial fibrosis is more significant in these patients than even the most pronounced cardiac hypertrophy in competitive athletes. HCM is relatively common ( 1 in 500 of the general population) and in young adults its mortality is 1 to $6 \%$. It is very difficult to distinguish $\mathrm{HCM}$ from normal compensatory hypertrophy in athletes in its early stage. After a 2-3 month sports activity free period suspected cases can be identified by echocardiographic studies, since this hypertrophy is not reversible. In athletes with HCM the effects of compensatory hypertrophy (athlete's heart) and pathological hypertrophy can add up and result in a dangerous increase of repolarization inhomogeneity forming a significant arrhythmia substrate. In addition to HCM, other pathological anomalies have been associated with sudden cardiac death in athletes [6, 30, 37], including congenital coronary artery anomalies, myocarditis, Wolff-Parkinson-White and Brugada syndromes, commotio cordis, sarcoidosis, aortic stenosis and arrhythmogenic right ventricular cardiomyopathy $[7,44]$. Interestingly, ARVC is regarded as the most common known cause for sudden cardiac death in competitive athletes in Italy, possibly due to the long-standing 30-year systematic athletic assessment program in that country that identified and prevented athletes with HCM from further participation in competitive sports $[15,35]$. 
Genetic defects

Fortunately, the prevalence of genetic defects leading to serious or subclinical repolarization disturbances is relatively low. The various types of congenital long QT syndromes have an estimated prevalence of 1:5000 in the general population. Studies on competitive athletes indicated similar prevalence $[4,25]$. Approximately $10 \%$ of patients with long QT syndrome die due to sudden cardiac death. The significance of congenital QT syndrome in athletes is augmented since the repolarization disturbance occurs in individuals who have a somewhat impaired repolarization reserve on the basis of cardiac hypertrophy. Therefore, mutations that would otherwise cause only mild abnormalities of repolarization can lead to serious arrhythmias in these athletes. This scenario is very likely when mutations occur in genes encoding proteins forming the alpha (KvLQT1) and/or beta (minK) subunits for $\mathrm{I}_{\mathrm{Ks}}$. In this case the reduced $\mathrm{I}_{\mathrm{Ks}}$ current (adding to the reduction in $\mathrm{I}_{\mathrm{Ks}}$ caused by cardiac hypertrophy) would not be able to compensate for prolonged repolarization caused by increased $\mathrm{I}_{\mathrm{Ca}, \mathrm{L}}$ current following an elevation in the sympathetic tone.

Another condition that can pose a threat to athletes that is even higher than in the general population is catecholaminergic polymorphic ventricular tachycardia (CPVT), [7]. CPVT is a serious abnormality that is related to mutations in genes either encoding proteins of the sarcoplasmic reticulum calcium releasing channels (RYR-gene) or calcium binding proteins (CASQ2). The increased sympathetic tone (during sports activities and training) results in calcium release from the SR to the cytoplasm in CPVT even during diastole. These events can initiate trigger extrasystoles that can initiate serious arrhythmias via the mechanism detailed earlier. In athletes with cardiac hypertrophy, where repolarization reserve can be impaired, the compensation of the process favouring depolarization in CPVT is reduced and consequently extrasystoles can form more easily.

Seemingly harmless medications

It is known that a number of drugs can block the fast component of the delayed rectifier potassium $\left(\mathrm{I}_{\mathrm{Kr}}\right)$ current, conducted by hERG channels, that leads to repolarization prolongation and can sometimes result in proarrhythmic side effects and very rarely in sudden cardiac death. Several frequently used non-cardiac drugs, including $\mathrm{H}_{1}$ antihistamines and antibiotics, have been shown to possess such side effects $[2,8]$. These compounds are not listed as doping agents and therefore can be administered to athletes. However, competitive 
athletes who have impaired repolarization reserve as a consequence of cardiac hypertrophy, the possible proarrhythmic side effects of these drugs can be augmented.

It is essential to emphasize that a number of compounds frequently used by athletes entered the market when drug safety studies, including those looking at QT prolonging effects, were less rigorous. Therefore it cannot be ruled out that some of these compounds in conjunction with other factors can contribute to the development of lethal ventricular arrhythmias in athletes with impaired repolarization reserve. For example, our preliminary data indicates that diclofenac moderately inhibits $\mathrm{I}_{\mathrm{Kr}}$ in isolated dog ventricular myocytes. In this context, the careful investigation and characterization of the effects of non-steroid antiinflammatory drugs (NSAIDs) on ventricular repolarization seems justified, even if these effects are found to be marginal. Athletes use NSAIDs very often and in large doses to treat different sports injuries while relatively little is known about the cardiac electrophysiologic effects of these compounds. Recently, celecoxib has been shown to inhibit rat Kv2.1 channels, indicating that NSAIDs can indeed block certain potassium channels [20], however, inhibition of $\mathrm{I}_{\mathrm{Kr}}$ still remains one of the most important proarrhythmic adverse effects of cardiac and non-cardiac therapeutic compounds.

Hypokalaemia

Hypokalaemia can develop during intense sports activities in case fluid replenishment is not adequate. The repolarization disturbance augmenting effect of hypokalaemia is well characterized and can also contribute to pathologically altered repolarization in athletes with cardiac hypertrophy. Reduction in extracellular potassium concentration leads to a substantial action potential prolongation that is partly due to decreased $\mathrm{I}_{\mathrm{Kr}}$ and $\mathrm{I}_{\mathrm{K} 1}$ in the late repolarization phase of the action potential.

\section{Doping}

Doping is primarily a problem associated with high level competitive sports and with body building activities [18]. Since the application of doping agents is illegal there is few reliable data available in the literature on this subject. However, it is known that steroids used for doping purposes can lead to skeletal and cardiac muscle hypertrophy [34, 36]. A similar effect can be attributed to the application of growth hormone. Therefore, the chronic administration of certain doping agents can contribute to the prolongation of repolarization and can increase 
inhomogeneity of repolarization, creating a substrate for serious ventricular arrhythmia generation. Amphetamine-type doping compounds can promote arrhythmia generation via another mechanism. These drugs can increase intracellular cAMP levels and, similarly to increased sympathetic tone, can promote the development of trigger extrasystoles that may induce lethal arrhythmias in individuals with inhomogenous ventricular repolarization (athlete's heart).

Dietary constituents

Athletes, especially competitive athletes frequently apply special diets, dietary supplements and vitamins, however, little is known about their cardiac electrophysiological effects. Importantly, according to animal experimental evidence, soy products can increase cardiac hypertrophy and worsen heart failure [41]. These effects were more robust in male than in female animals $[16,52]$. Notably, sudden cardiac death in athletes due to cardiac hypertrophy is more frequent in men. Interesting data in connection with grapefruit consumption have also been published. According to these results, significant prolongation of the QT interval was detected after the ingestion of 1 liter freshly squeezed grapefruit juice and this repolarization prolonging effect was attributed to the potassium channel blocking $\left(\mathrm{I}_{\mathrm{Kr}}\right)$ effect of certain flavonoids present in grapefruit in large quantities [53]. It is also known that grapefruit juice interferes with the metabolism of numerous drugs and compounds by inhibiting the 3A4 isoenzyme of the cytochrome P450 system, leading to potentially unexpected effects when grapefruit juice consumption is parallel with administration of certain drugs and other chemical compounds including different dietary constituents. It should be emphasized that we know so little about the electrophysiological effects of food additives, preservatives, colouring agents that the above-mentioned examples might only represent the tip of the iceberg.

Bad luck

As illustrated on Figure 1, two main underlying factors are needed for the development of an arrhythmia. On the one hand, a certain degree of inhomogeneity of ventricular repolarization is needed that is closely connected to the length of the vulnerability period. A larger ventricular repolarization inhomogeneity results in a longer vulnerability period (substrate). On the other hand, the more frequently extrasystoles occur, the more likely they will develop 
during the vulnerability period inducing chaotic ventricular tachycardia or ventricular fibrillation. On the level of the individual, however, as a contributor factor, misfortune should be emphasized as the most important factor, since in case the trigger extrasystole occurs even a fraction of a millisecond prior to or later than the vulnerability period, serious cardiac arrhythmia will not develop. In other words, even if all the objective prerequisites for arrhythmia development exist (substrate + trigger), the exact but random timing of the trigger extrasystoles will determine the induction of a lethal arrhythmic attack in a given individual. In the statistical sense, however, in competitive athletes compared to the average population, in connection with the increased repolarization inhomogeneity due to cardiac hypertrophy, the vulnerability period is probably significantly longer and the sympathetic tone and consequently ectopic activity is more often increased for longer periods as a result of regular training and competitive game situations. Thus the risk for sudden cardiac death based on repolarization abnormalities in competitive athletes should be higher than in the healthy average population (first two columns of Fig. 6). The subsidiary risk factors (listed in the third column of Fig. 6) contribute to the increased risk associated with competitive sport in an additive manner, resulting in an increased chance for serious arrhythmia development in athletes.

\section{Prevention of sudden cardiac death in athletes}

To avoid any misconception it should be declared again that sports activities monitored by expert sports doctors improve life expectancy and quality of life due to their beneficial effects on metabolism and on the cardiovascular, immune and respiratory systems. When the prevalence of sudden cardiac death is investigated in the whole population, it is found that in the majority of cases the cause has an ischaemic origin due to coronary artery disease and in only approximately $5 \%$ of sudden cardiac death cases cannot be explained clearly and have no structural heart disease in the background $[11,45]$. Regular sports activities are very useful in the prevention of ischaemic heart disease and only represent a very low increase in risk for a small group of sudden cardiac deaths. However, the nature and mechanism of this small increase has to be understood and recognized in order to appropriately address this problem and to look for sensible solutions.

One of the main obstacles of sudden cardiac death prevention is its fortunately very low incidence (1:50 $000-1: 100000$ annually) making it hard to properly apply statistics, to draw general conclusions and to understand the mechanisms. A number of legal debates indicate 
that the banning of a top competitive athlete from sports is not without problems and cannot be carried out based solely on suspected causes [28]. Detailed official statements on cardiovascular problems in sports were published in documents of the conference of the American College of Cardiology in Bethesda and of the congress of the European Society of Cardiology, both in $2005[15,27]$. The incidence of sudden cardiac death in Italy has been significantly reduced in the past 25 years with the application of a relatively low cost $(70$ euros per athlete) and thorough cardiovascular screening program [13]. It would be possible to successfully screen for the majority of HCM, long QT and AVRS cases using echocardiographical and ECG measurements that are more thorough than the currently used methods. More careful consideration before the prescription of drugs and application of dietary supplements that might prolong repolarization could also bring further results. Novel diagnostic tools, such as the calculation of the short-term beat-to-beat temporal variability of the QT interval or the application of moderate provocation tests under intensive care monitoring could also be considered. In case the suspicion of risk amplification is well established in an individual, more costly genetical screening can also be considered.

\section{Summary}

Unless autopsy findings establish the exact cause of sudden cardiac death in an athlete beyond any doubt, the reasons should be sought in repolarization abnormalities rather than in an unconfirmed ischaemic origin. Accordingly, more attention should be paid to non-invasive cardiac electrophysiological investigations during preventive sports medicine activities and to the theoretical and practical cardiac electrophysiological postgraduate training of sports doctors. Importantly, unexpected and unexplained syncopes in the anamnesis of athletes should be taken seriously and thoroughly investigated. 
Varró \& Baczkó: Sudden cardiac death in athletes

\section{Acknowledgments}

This study was supported by grants from the National Office for Research and Technology (NKTH CARDIO 08), János Bolyai Research Scholarship (I.B.), Hungarian National Research Foundation (OTKA CNK-77855) and by the European Commission preDiCT grant (DG-INFSO - 224381). 


\section{References}

1. Akar FG, Yan GX, Antzelevitch C, Rosenbaum DS (2002) Unique topographical distribution of $\mathrm{M}$ cells underlies reentrant mechanism of torsade de pointes in the long-QT syndrome. Circulation 105:1247-1253

2. Anderson ME, Mazur A, Yang T, Roden DM (2001) Potassium current antagonist properties and proarrhythmic consequences of quinolone antibiotics. J Pharmacol Exp Ther 296:806-810

3. Atchley AE, Douglas PS (2007) Left ventricular hypertrophy in athletes: morphologic features and clinical correlates. Cardiol Clin 25:371-382

4. Basavarajaiah S, Wilson M, Whyte G, Shah A, Behr E, Sharma S (2007) Prevalence and significance of an isolated long QT interval in elite athletes. Eur Heart J 28:29442949

5. Basavarajaiah S, Wilson M, Whyte G, Shah A, McKenna W, Sharma S (2008) Prevalence of hypertrophic cardiomyopathy in highly trained athletes. J Am Coll Cardiol 51:1033-1039

6. Basso C, Corrado D, Thiene G (2007) Arrhythmogenic right ventricular cardiomyopathy in athletes: diagnosis, management, and recommendations for sport activity. Cardiol Clin 25:415-422

7. Benton NG, Maginot KR (2007) Sudden cardiac death in young athletes: trying to find the needle in the haystack. Wisconsin Med J 106:335-342

8. Berul CI, Morad M (1995) Regulation of potassium channels by nonsedating antihistamines. Circulation 91:2220-2225

9. Blaustein MP, Lederer WJ (1999) Sodium/calcium exchange: its physiological implications. Physiol Rev 79:763-854

10. Bos JM, Towbin JA, Ackerman MJ (2009) Diagnostic, prognostic, and therapeutic implications of genetic testing for hypertrophic cardiomyopathy. J Am Coll Cardiol $54: 201-211$

11. Campbell RW (1983) Treatment and prophylaxis of ventricular arrhythmias in acute myocardial infarction. Am J Cardiol 52:55C-59C

12. Cerbai E, Pino R, Porciatti F, Sani G, Toscano M, Maccherini M, Giunti G, Mugelli A (1997) Characterization of the hyperpolarization-activated current, I(f), in ventricular myocytes from human failing heart. Circulation 95:568-571 
13. Corrado D, Basso C, Schiavon M, Thiene G (1998) Screening for hypertrophic cardiomyopathy in young athletes. New Engl J Med 339:364-369

14. Corrado D, Michieli P, Basso C, Schiavon M, Thiene G, Hon FRCP (2007) How to screen athletes for cardiovascular diseases. Cardiol Clin 25:391-397

15. Corrado D, Pelliccia A, Bjørnstad HH, Vanhees L, Biffi A, Borjesson M, PanhuyzenGoedkoop N, Deligiannis A, Solberg E, Dugmore D, Mellwig KP, Assanelli D, Delise P, van-Buuren F, Anastasakis A, Heidbuchel H, Hoffmann E, Fagard R, Priori SG, Basso C, Arbustini E, Blomstrom-Lundqvist C, McKenna WJ, Thiene G, Study Group of Sport Cardiology of the Working Group of Cardiac Rehabilitation and Exercise Physiology and the Working Group of Myocardial and Pericardial Diseases of the European Society of Cardiology. (2005) Cardiovascular pre-participation screening of young competitive athletes for prevention of sudden death: proposal for a common European protocol. Consensus Statement of the Study Group of Sport Cardiology of the Working Group of Cardiac Rehabilitation and Exercise Physiology and the Working Group of Myocardial and Pericardial Disease of the European Society of Cardiology. Eur Heart J 26:516-524

16. Csáky I, Fekete S (2004) Soybean: feed quality and safety. Part 1: biologically active components. A review. Acta Vet Hung 52:299-313

17. de Groot SHM, Schoenmakers M, Molenschot MMC, Leunissen JDM, Wellens HJJ, Vos MA (2000) Contractile adaptations preserving cardiac output predispose the hypertrophied canine heart to delayed afterdepolarization-dependent ventricular arrhythmias. Circulation 102:2145-2151

18. de Rose EH (2008) Doping in athletes - an update. Clin Sports Med 27:107-130

19. DiFrancesco D, Borer JS (2007) The funny current: cellular basis for the control of heart rate. Drugs 67.Suppl 2:15-24

20. Frolov RV, Berim IG, Singh S (2008) Inhibition of delayed rectifier potassium channels and induction of arrhythmia: a novel effect of celecoxib and the mechanism underlying it. J Biol Chem 283:1518-1524

21. Gallacher DJ, Van de Water A, van der Linde H, Hermans AN, Lu HR, Towart R, Volders PG (2007) In vivo mechanisms precipitating torsades de pointes in a canine model of drug-induced long-QT1 syndrome. Cardiovasc Res 76:247-256

22. Halle M, Huonker M, Hohnloser SH, Alivertis M, Berg A, Keul J (1999) QT dispersion in exercise-induced myocardial hypertrophy. Am Heart J 138:309-312 
23. Hart G (2003) Exercise-induced cardiac hypertrophy: a substrate for sudden death in athletes? Exp Physiol 88:639-644

24. Janse MJ (2004) Electrophysiological changes in heart failure and their relationship to arrhythmogenesis. Cardiovasc Res 61:208-217

25. Kapetanopoulos A, Kluger J, Maron BJ, Thompson PD (2006) The congenital long QT syndrome and implications for young athletes. Med Sci Sports Exerc 38:816-825

26. Kavazis AN (2009) Exercise preconditioning of the myocardium. Sports Med 39:923935

27. Maron BJ, Douglas PS, Graham TP, Nishimura RA, Thompson PD (2005) Task force 1: preparticipation screening and diagnosis of cardiovascular disease in athletes. J Am Coll Cardiol 45:1322-1326

28. Maron BJ, Mitten MJ, Quandt EF, Zipes DP (1998) Competitive athletes with cardiovascular disease - the case of Nicholas Knapp. New Engl J Med 339:1632-1635

29. Maron BJ, Pelliccia A (2006) The heart of trained athletes: cardiac remodeling and the risks of sports, including sudden death. Circulation 114:1633-1644

30. Maron BJ (2007) Hypertrophic cardiomyopathy and other causes of sudden cardiac death in young competitive athletes, with considerations for preparticipation screening and criteria for disqualification. Cardiol Clin 25:399-414

31. Mehta PA, Dubrey SW, McIntyre HF, Walker DM, Hardman SM, Sutton GC, McDonagh TA, Cowie MR (2008) Mode of death in patients with newly diagnosed heart failure in the general population. Eur J Heart Fail 10:1108-1116

32. Paolo FM, Pelliccia A (2007) The "Athlete's heart": relation to gender and race. Cardiol Clin 25:383-389

33. Parratt JR, Végh Á (1997) Delayed protection against ventricular arrhythmias by cardiac pacing. Heart 78:423-425

34. Payne JR, Kotwinski PJ, Montgomery HE (2004) Cardiac effects of anabolic steroids. Heart 90:473-475

35. Pelliccia A, Maron BJ (1995) Preparticipation cardiovascular evaluation of the competitive athlete: perspectives from the 30-year Italian experience. Am J Cardiol 75:827-829

36. Pereira PP, Chaves EA, Costa-e-Sousa RH, Masuda MO, Campos de Carvalho AC, Nascimento JHM (2006) Cardiac autonomic dysfunction in rats chronically treated with anabolic steroid. Eur Appl Physiol 96:487-494 
37. Pigozzi F, Rizzo M (2008) Sudden death in competitive athletes. Clin Sports 27:153181

38. Scharhag J, Schneider G, Urhausen A, Rochette V, Kramann B, Kindermann W (2002) Athlete's heart. J Am Coll Cardiol 40:1856-1863

39. Sipido KR, Volders PG, Vos MA, Verdonck F (2002) Altered $\mathrm{Na} / \mathrm{Ca}$ exchange activity in cardiac hypertrophy and heart failure: a new target for therapy? Cardiovasc Res 53:782-805

40. Sperelakis N, Katsube Y, Yokoshiki H, Sada H, Sumii K (1996) Regulation of the slow $\mathrm{Ca}^{++}$channels of myocardial cells. Mol Cell Biochem 163-164:85-98

41. Stauffer BL, Konhilas JP, Luczak ED, Leinwand LA (2006) Soy diet worsens heart disease in mice. J Clin Invest 116:209-216

42. Stengl M, Ramakers C, Donker DW, Nabar A, Rybin AV, Spätjens RL, van der Nagel T, Wodzig WK, Sipido KR, Antoons G, Moorman AF, Vos MA, Volders PG (2006) Temporal patterns of electrical remodelling in canine ventricular hypertrophy: focus on IKs downregulation and blunted beta-adrenergic activation. Cardiovasc Res 72:90100

43. Stillitano F, Lonardo G, Zicha S, Varro A, Cerbai E, Mugelli A, Nattel S (2008) Molecular basis of funny current (If) in normal and failing human heart. J Mol Cell Cardiol 45:289-299

44. Thiene G, Corrado D, Basso C (2007) Arrhythmogenic right ventricular cardiomyopathy/dysplasia. Orphanet J Rare 2:45-60

45. Thomas AC, Knapman PA, Krikler DM, Davies MJ (1988) Community study of the causes of 'natural' sudden death. BMJ 297:1453-1457

46. Thomsen MB, Verduyn SC, Stengl M, Beekman JD, de Pater G, van Opstal J, Volders PG, Vos MA (2004) Increased short-term variability of repolarization predicts dsotalol-induced torsades de pointes in dogs. Circulation 110:2453-2459

47. Turkmen M, Barutcu I, Esen AM, Ocak Y, Melek M, Kaya D, Karakaya O, Saglam M, Basaran Y (2004) Assessment of QT interval duration and dispersion in athlete's heart. J Int Med Res 32:626-632

48. Volders PG, Stengl M, van Opstal JM, Gerlach U, Spätjens RL, Beekman JD (2003) Probing the contribution of $\mathrm{I}_{\mathrm{Ks}}$ to canine ventricular repolarization: key role for betaadrenergic receptor stimulation. Circulation 107:2753-2760

49. Volders PGA, Sipido KR, Vos MA, Kulcsár A, Verduyn SC, Wellens HJJ (1998) Cellular basis of biventricular hypertrophy and arrhythmogenesis in dogs with chronic 
complete atrioventricular block and acquired torsade de pointes. Circulation 98:11361147

50. Volders PG, Sipido KR, Vos MA, Spätjens RL, Leunissen JD, Carmeliet E, Wellens HJ (1999) Downregulation of delayed rectifier $\mathrm{K}^{+}$currents in dogs with chronic complete atrioventricular block and acquired torsades de pointes. Circulation 100:2455-2461

51. Vos MA, de Groot SH, Verduyn SC, van der Zande J, Leunissen HD, Cleutjens JP, van Bilsen M, Daemen MJ, Schreuder JJ, Allessie MA, Wellens HJ (1998) Enhanced susceptibility for acquired torsade de pointes arrhythmias in the dog with chronic, complete AV block is related to cardiac hypertrophy and electrical remodeling. Circulation 98:1125-1135

52. Xin HB, Senbonmatsu T, Cheng DS, Wang YX, Copello JA, Ji GJ, Collier ML, Deng KY, Jeyakumar LH, Magnuson MA, Inagami T, Kotlikoff MI, Fleischer S (2002) Oestrogen protects KFBP12.6 null mice from cardiac hypertrophy. Nature 416:334337

53. Zitron E, Scholz E, Owen RW, Lück S, Kiesecker C, Thomas D, Kathöfer S, Niroomand F, Kiehn J, Kreye VA, Katus HA, Schoels W, Karle CA (2005) QTc prolongation by grapefruit juice and its potential pharmacological basis. HERG channel blockade by flavonoids. Circulation 111:835-838 


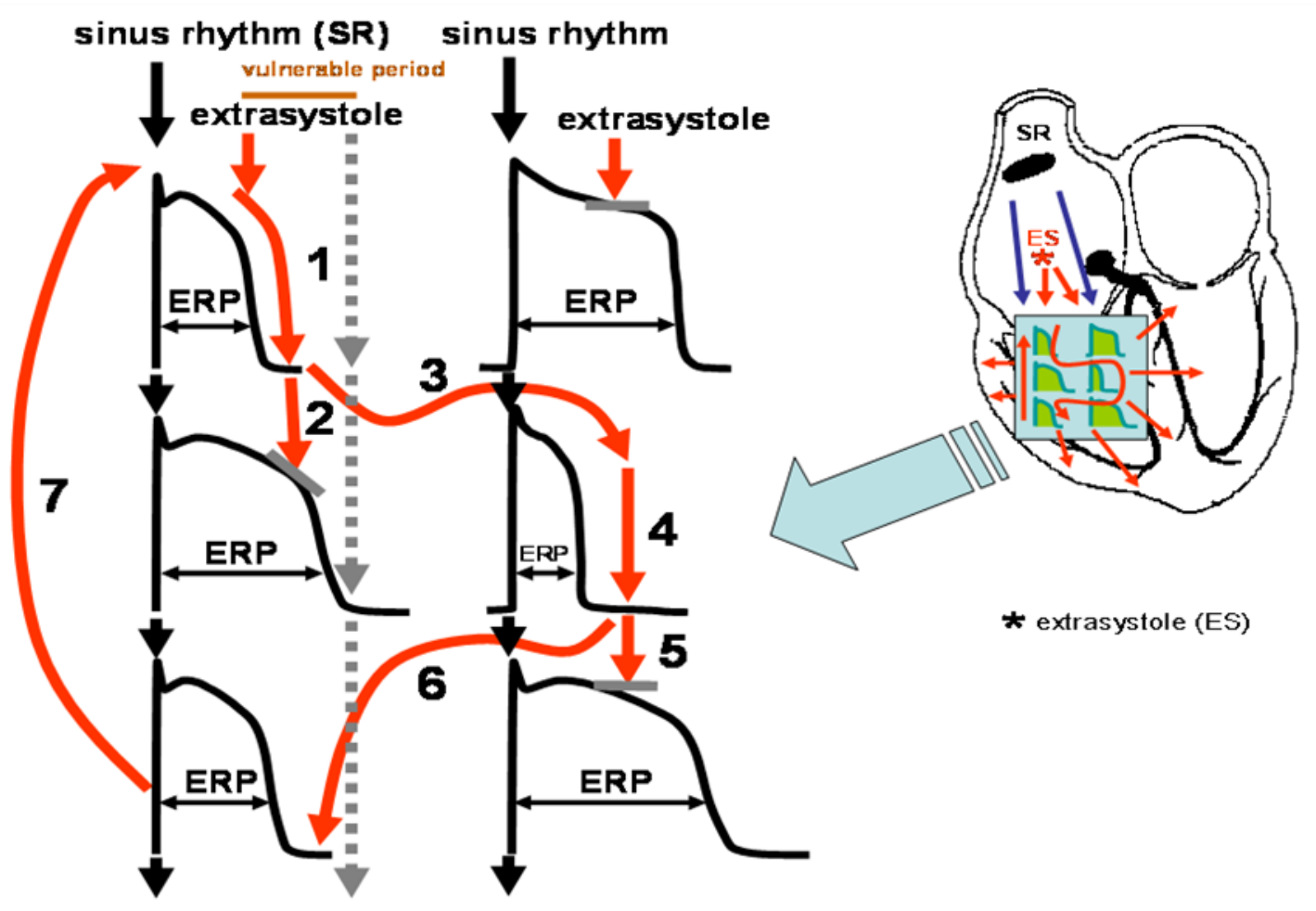

Figure 1. Schematic, simplified illustration of the mechanism of arrhythmia development due to increased repolarization dispersion ("arrhythmia substrate", i.e. the prerequisite for arrhythmia development), represented by action potentials with different durations on figure. In normal circumstances, sinus impulses (black arrows) propagate through the atrial and ventricular tissue and conduction system via physiological pathways. An early ectopic impulse ("trigger", i.e. the actual specific factor that initiates the arrhythmia; red arrows) or a preceding extrasystole can only propagate via pathways where cells are not refractory and their action potentials are in their vulnerable periods $(1,3,4,6)$, whereas it is blocked in directions where the action potentials of cells are in the refractory period ( 2 and 5 ). The abnormal impulse can travel re-entry paths created by inhomogenous repolarization (7). See text for further details. ES: extrasystole; ERP: effective refractory period. 


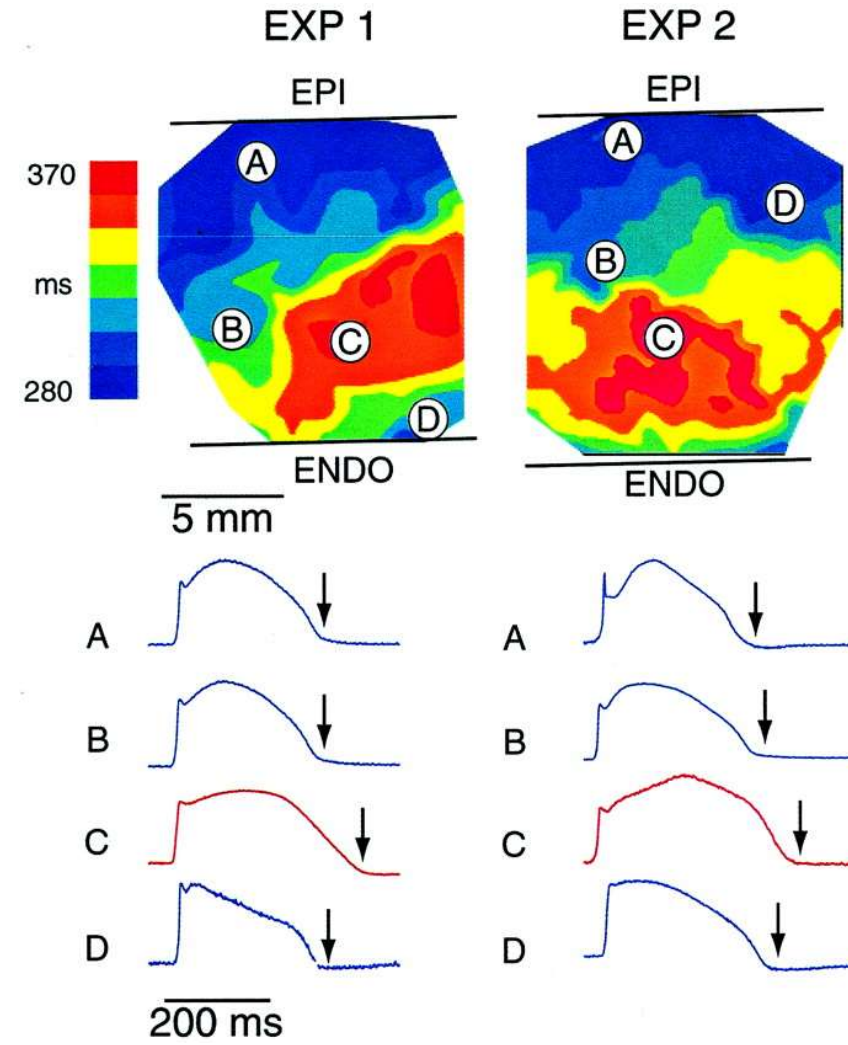

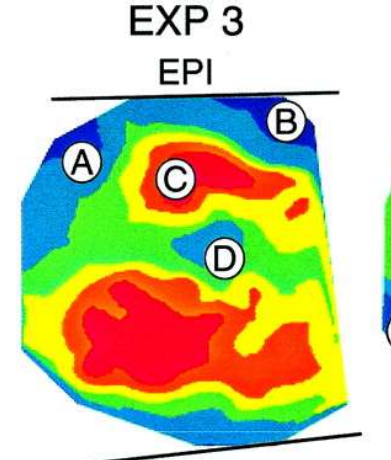

ENDO
EXP 4
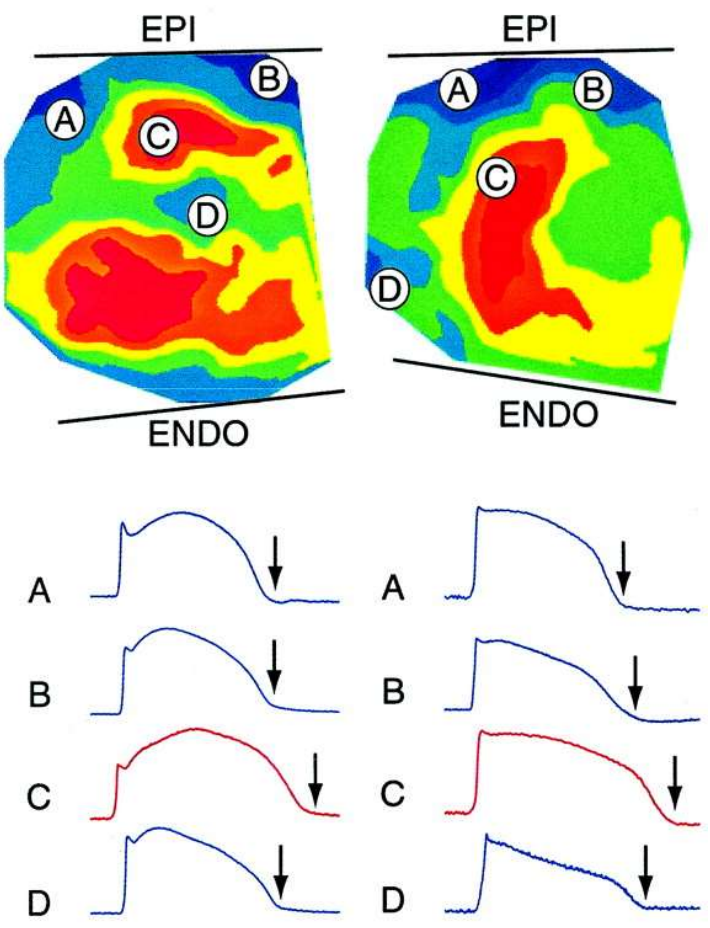

Figure 2. Experimental demonstration of spatial differences in length of repolarization. Upper panel illustrates increased transmural heterogeneity of action potential durations using color codes (very long action potentials in red) in bradycardia and d-sotalol administration to mimic decreased repolarization reserve in the canine wedge LQT2 model. On lower panel optical action potentials are shown from selected transmural sites. Letters (A to D) on lower panel refer to areas on upper panel where representative optical action potentials were recorded from. Note the significant differences in the action potential duration (indicated by arrows) within relatively short distances and within the same transmural layer. Adapted from Akar et al., Circulation 2002, 105: 1247-53, with permission. 

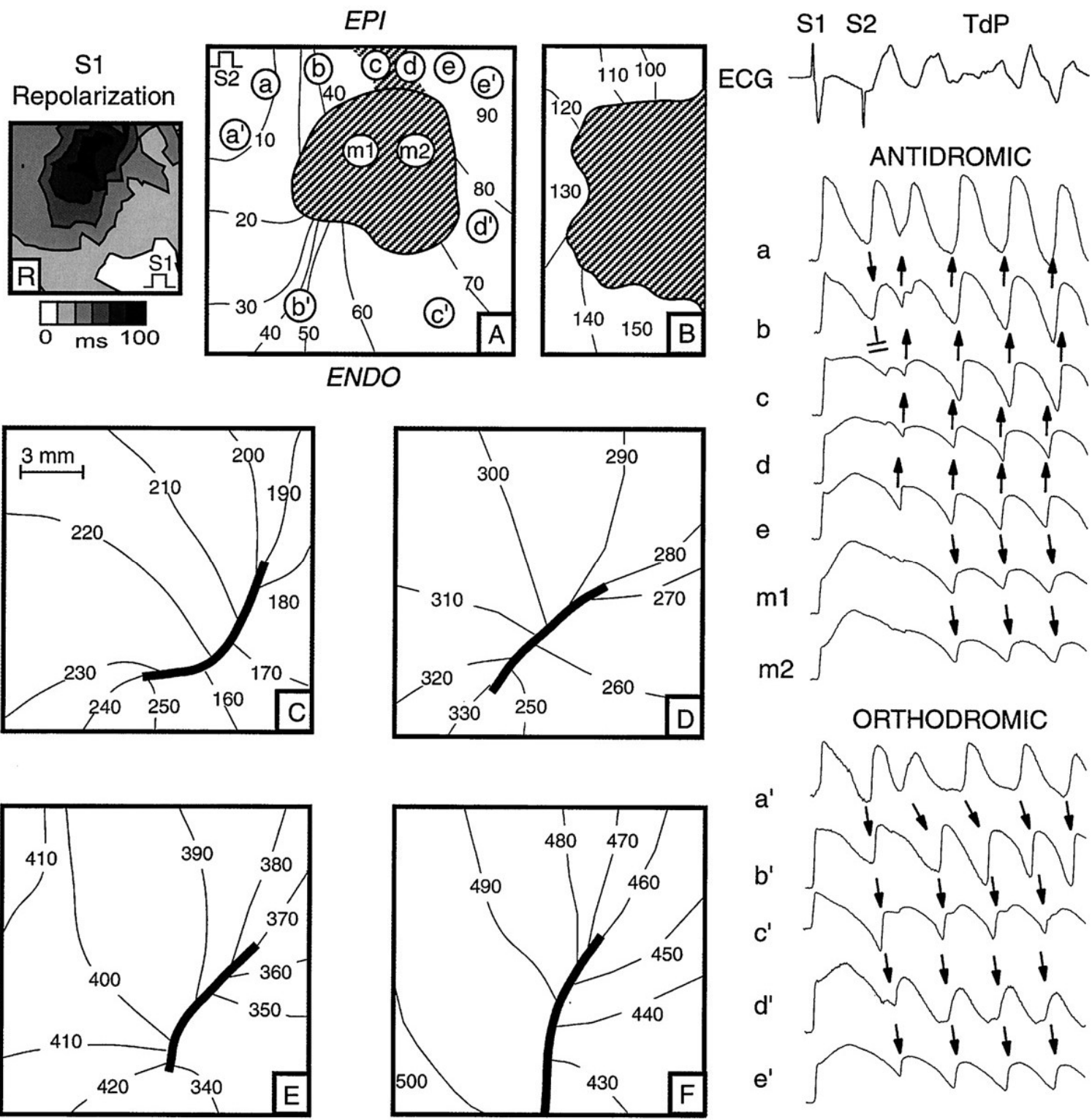

Figure 3. Experimental demonstration of the development of Torsades de Pointes arrhythmia induced by a premature extra stimulus (S2) in the canine wedge model during bradycardia and selective $\mathrm{I}_{\mathrm{Kr}}$ block by d-sotalol. First panel (R) shows repolarization map during S1-S1 pacing. Panels A to F show depolarization maps with isochrones with reference to the time of the S2 impulse. The S2 stimulus was applied on the epicardial surface (top left corner of panel A). Spatial differences in action potential duration created a region with delayed repolarization (middle region on $\mathrm{R}$ panel and $\mathrm{c}, \mathrm{d}, \mathrm{m} 1-\mathrm{m} 2$ regions on panel $\mathrm{A}$ ) around which the premature stimulus could propagate only in the orthodromic (counterclockwise) direction ( $\mathrm{a}^{\prime}$ to e') but not in the antidromic direction (a to e, conduction blocked in c,d and $\mathrm{m} 1, \mathrm{~m} 2$ regions). Former sites of block (c, d on panel A) regained excitability and the impulse propagated back from site e to a (panel B), completing a re-entry circle. Initial broad areas of functional conduction block were replaced by functional lines of block during subsequent beats of the re-entry arrhythmia (panels C to F). Adapted from Akar et al., Circulation 2002, 105: 1247-53, with permission. 

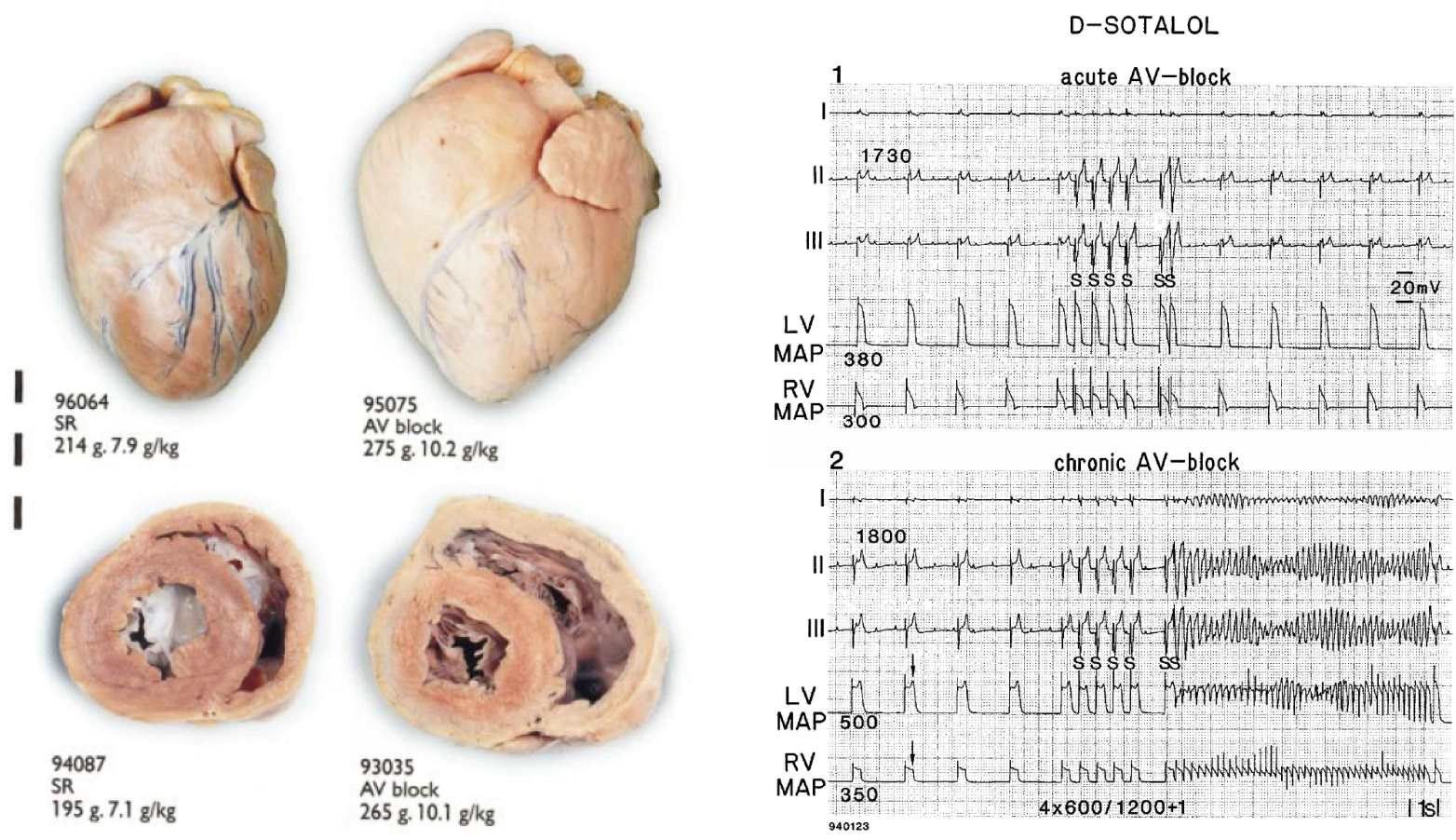

Figure 4. Chronic AV-block leads to cardiac hypertrophy in dogs. Challenging the heart with the selective $\mathrm{I}_{\mathrm{Kr}}$ blocker d-sotalol provoked Torsades de Pointes arrhythmias only in dogs with chronic AV-block and impaired repolarization reserve. Adapted from Vos et al., Circulation 1998, 98: 1125-35, with permission. 

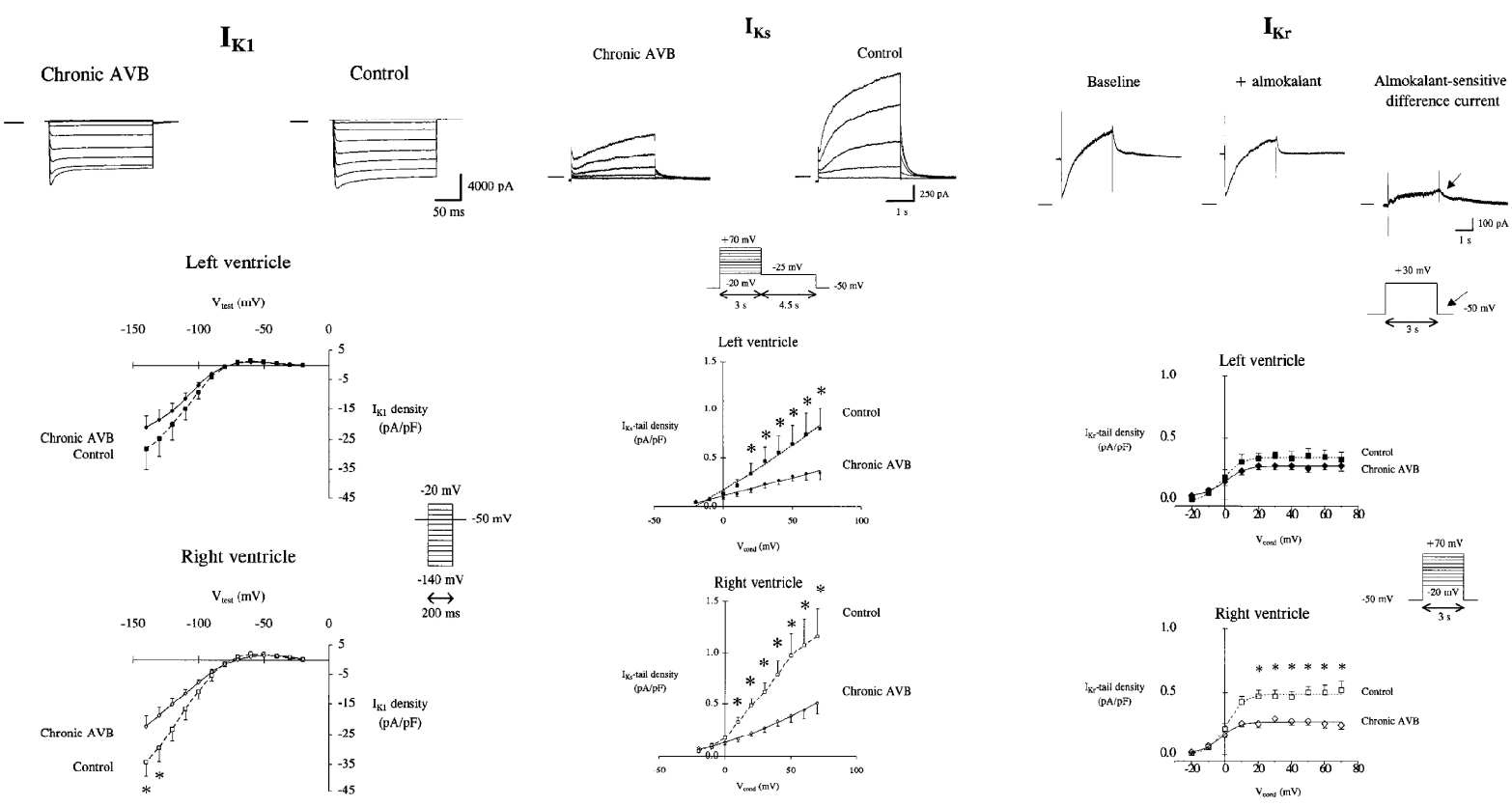

Figure 5. Experimental evidence for downregulation of $I_{K 1}, I_{K s}$ and $I_{K r}$ in hypertrophic dog hearts with chronic AV-block, leading to reduced repolarization reserve. Adapted from Volders et al., Circulation 1999, 100: 2455-2461, with permission. 


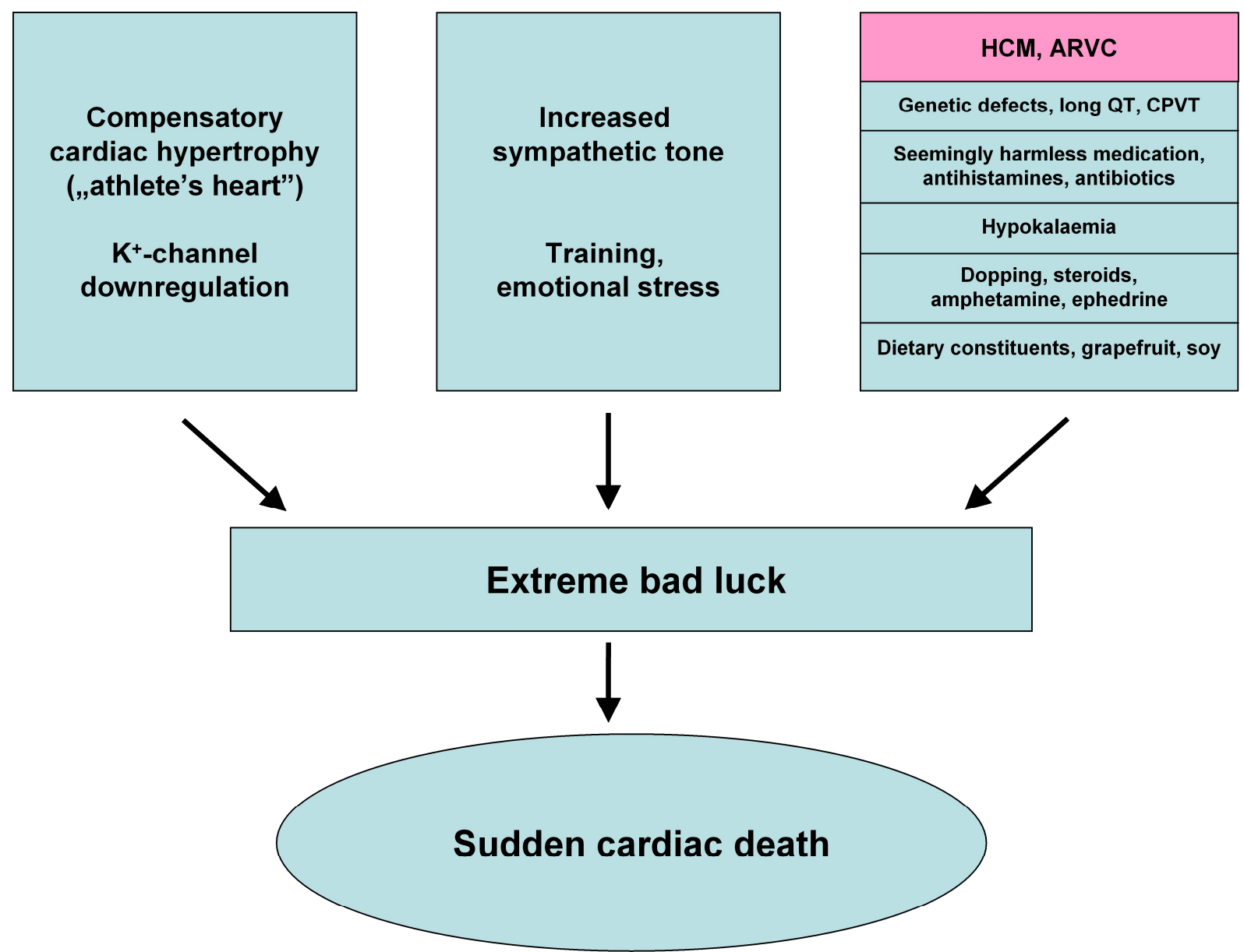

Figure 6. Summary of risk factors most likely involved in sudden cardiac death of competitive athletes. HCM: hypertrophic cardiomyopathy; ARVC: arrhythmogenic right ventricular cardiomyopathy; CPVT: catecholaminergic polymorphic ventricular tachycardia. 